\title{
Seismic Landslide Susceptibility Assessment Using Principal Component Analysis And Support Vector Machine
}

\section{Ziyao Xu}

Shanghai Jiaotong University: Shanghai Jiao Tong University

Ailan Che ( $\nabla$ alche@sjtu.edu.cn )

Shanghai Jiao Tong University https://orcid.org/0000-0003-3523-2832

Yanbo Cao

Yunnan Earthquake Administration

Fanghao Zhang

Yunnan Earthquake Administration

\section{Research Article}

Keywords: Landslide susceptibility, Earthquake, Dayong Expressway, Support vector machine (SVM), Principal component analysis (PCA)

Posted Date: September 7th, 2021

DOI: https://doi.org/10.21203/rs.3.rs-761260/v1

License: (c) (i) This work is licensed under a Creative Commons Attribution 4.0 International License. Read Full License 


\title{
Seismic landslide susceptibility assessment using principal component
}

\section{analysis and support vector machine}

\author{
Ziyao Xu ${ }^{\mathrm{a}}$, Ailan Che ${ }^{\mathrm{a} *}$, Yanbo Cao ${ }^{\mathrm{b}}$, Fanghao Zhang ${ }^{\mathrm{b}}$ \\ a. School of Naval Architecture, Ocean and Civil Engineering, Shanghai Jiao Tong University, 800 Dongchuan Road, Shanghai \\ 200240, China. E-mail address: xuziyaoxzy@sjtu.edu.cn \\ a. School of Naval Architecture, Ocean and Civil Engineering, Shanghai Jiao Tong University, 800 Dongchuan Road, Shanghai \\ 200040, China. E-mail address: alche@sjtu.edu.cn* Corresponding author. \\ b. Earthquake Administration of Yunnan Province, Kunming 650224, China
}

\section{Abstract}

Seismic landslides are dangerous natural hazards, causing immense damage in terms of human lives and property. Susceptibility assessment of earthquake triggered landslide is the scientific premise and theoretical basis of disaster emergency management of engineering. The aim of this study is to applied the seismic landslide susceptibility model to Dayong Expressway in Chenghai area prone to frequent earthquakes. Support vector machine is used to establish the assessment model based on the data of 716 landslides caused by Ludian Ms6.5 earthquake in 2014. To improve the universality of the assessment model in different regions. Principal component analysis (PCA) is used for reducing the dimension of landslide conditioning factors and weaking difference of the regional characteristics between historical earthquake regions with Dayong expressway area. To applied the SVM model for seismic landslide susceptibility in Dayong Expressway region where the conditioning factors information is similar to Ludian area. Gutenberg-Richter model and Dieterich model are used to assume an earthquake in Chenghai area for landslide susceptibility assessment. Inverse distance weight (IDW) method is used for assessing the landslide risk class of Dayong Expressway. The results show that the "Very high" landslide susceptibility class account for $0.63 \%$ of Chenghai area. The seismic landslide has the most obvious 
impact on the middle $13 \mathrm{~km}$ section of Dayong expressway and this section account for $8.9 \%$ is defined as high-risk class. The study verifies the practicability of the seismic landslide susceptibility model based on machine learning and provides constructive reference for the susceptibility assessment of engineering facilities under earthquake.

Keywords Landslide susceptibility; Earthquake; Dayong Expressway; Support vector machine (SVM); Principal component analysis (PCA);

\section{Introduction}

Landslides represent one of the most destructive and frequent natural hazard phenomena reported worldwide (Ge et al. 2018). It creates a significant constraint in the pace of economic development due to the disruption of infrastructures and blockade of transportation facilities (Vkpa et al. 2019). Landslide susceptibility assessment is an effective approach to reduce damage from landslides to public property, infrastructure, and people's lives (Zhao et al. 2021) which has been widely used in restrict and affect project planning (Wu et al. 2020; Moragues et al. 2021).

A wide range of qualitative and quantitative approaches have been used for landslide susceptibility assessment (Zhang et al. 2012). The approach mainly includes assessments based on expert experience (Eeckhaut et al. 2005) and sophisticated mathematical methods (Bai. 2010). The assessments based on expert experience contain discriminant analysis (Carrara et al. 1999), analytical hierarchy process (Kayastha et al. 2013). Methods based on experts' knowledge and experience, ratings by different experts often lead to different assessment results (He et al. 2019). The main mathematical and statistical methods include the logistic regression model (Lee et al. 2015), the weight of evidence method (Hong et al. 2017). These methods based on the available landslide data, assess various classifications of landslide influence 
factors, and figure out the correlation between landslide susceptibility and influence factors. However, these methods are not suitable for dealing with data imbalance and nonlinearity problems.

With the development of computing power, geospatial data, and artificial intelligence, many machine learning methods such as support vector machine (SVM), random forester (RF), boosted regression tree (BRT), artificial neural network (ANN) and recurrent neural networks (RNNs) (Wei et al. 2020) have been developed. The machine learning models performed better on nonlinear problems (Goetz et al, 2015; Pham et al, 2016). SVM becomes popular in the landslide susceptibility assessment due to its characteristics of small number of samples, nonlinearity, high dimension and fast learning capacity (Huang et al. 2018; Wang et al. 2019).

In the past decades, many studies have been conducted to assess the susceptibility of landslide using SVM or other machine learning methods (Zhang et al. 2012). The performance of the SVM and other different machine learning algorithms are compared in assessment of earthquake-triggered landslide susceptibility (Miloš et al. 2011; Xu et al. 2016; Chen et al. 2016). Zhou (2018) applied the SVM, ANN and a multivariate statistical model: the logistic regression for landslide susceptibility modeling. Hong, H (2017) proposed a hybrid modeling approach using support vector machines and random subspace and tested in the Wuning area to produce a landslide susceptibility map. Kamila (2016) used PCA to reduce redundant information and reduce computational time of SVM model. In addition, many studies assess the direct losses resulting from landslides to engineering such as expressway (Yusof et al.2014; Yusof et al. 2015; Zhang et al. 2019; Vkpa et al. 2019; Nanda et al. 2020). Yin (2020) combined the PCA and SVM model to the susceptibility mapping and zoning of highway landslide disasters in China. Most researches on landslides along the expressway based on historical landslides samples in the area.

However, previous studies on machine learning and SVM mostly focus on the accuracy comparison. 
Most of the studies focus on the assessment of landslide susceptibility in a certain area. Moreover, there are still few researches on the application of existing models to landslide susceptibility assessment in engineering. The limitation of these research is that the landslide susceptibility models are highly dependent on the number and distribution of landslide samples. Due to the unique topographical features of different areas on their own, it is difficult to apply the landslide susceptibility model from one area to another. Therefore, it is worth noting that use historical seismic landslide to establish the landslide susceptibility assessment model and apply this model for important engineering in earthquake-prone area.

This study focuses on the application of SVM model in seismic landslide susceptibility assessment along Dayong Expressway in affected region of Chenghai fault zone. The seismic landslide susceptibility model is established based on the 716 landslides data caused by Ludian earthquake in Yunnan Province and 10 influenced factors. PCA is adopted for reducing complexity of input variables and making the influence factor dimensionless. This model was applicated to the seismic landslide susceptibility assessment along Dayong Expressway in Chenghai area. Chenghai is an earthquake prone area, there have been many earthquakes in history. Lijiang section of Dayong expressway is located in the Chenghai fault zone developed area and parallel with the Chenghai fault. Moreover, the geological environment of this area is similar to that of Ludian area. In order to assess the seismic landslide susceptibility in Chenghai area, an earthquake was assumed near the Dayong Expressway. The SVM model is applied to assess the landslide susceptibility of Dayong expressway in the potential earthquake area and dividing the landslide susceptibility class of expressway.

\section{Study area}

Chenghai area are located on the northwest of Yunnan Province. Because of the relative movement of the Eurasian and Indian Plate, a series of N-S, N-W and N-E trending faults formed the diamond shaped 
Dali fault system (Wang et al. 1998). Affected by many active faults, strong earthquakes occur frequently in this area and the risk of geological disasters caused by earthquake is very serious. The geographical location of Chenghai area is shown in Figure. 1

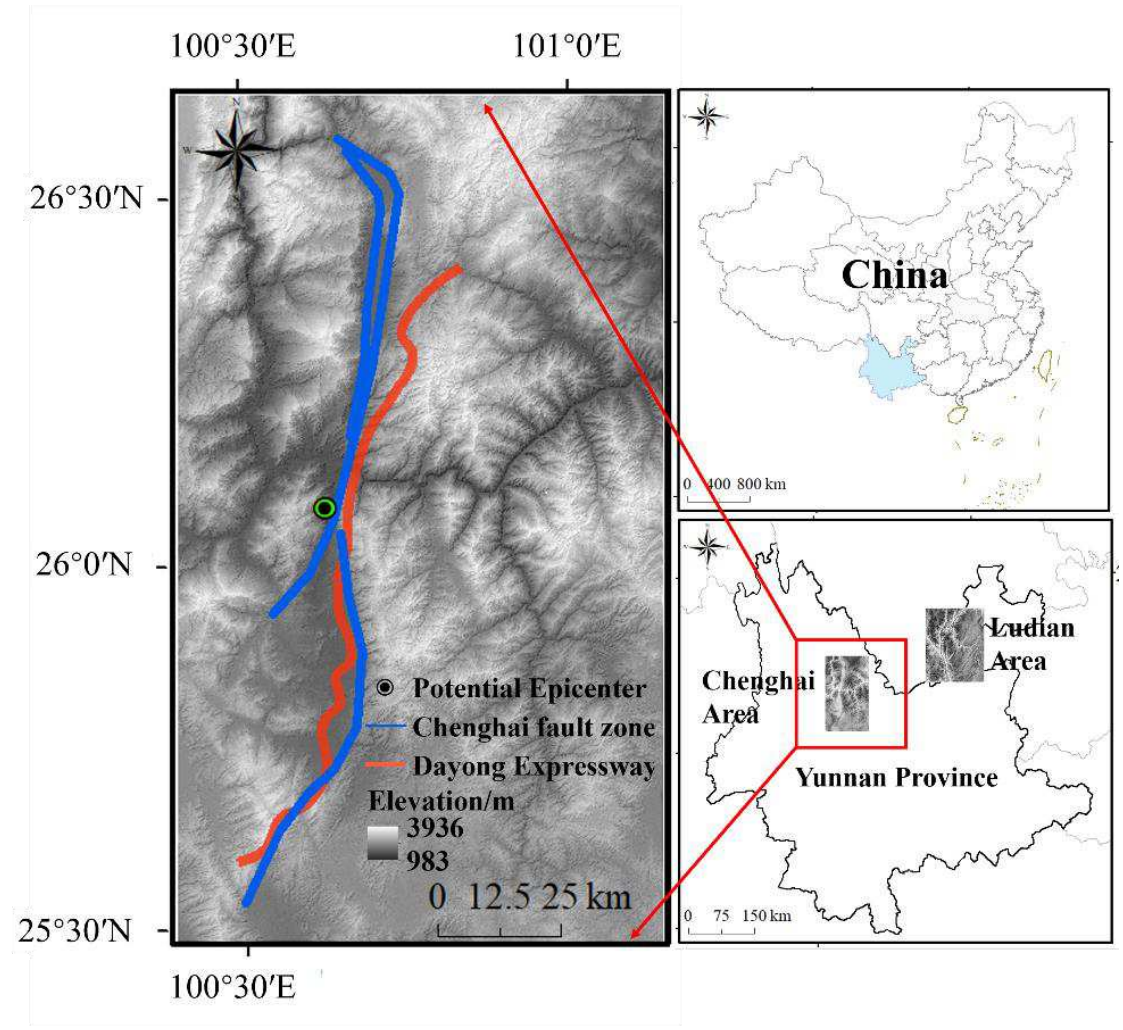

Fig.1. Expressway and Chenghai fault zone of study area

\section{Methodology}

In this study, two methods, namely, Principal component analysis (PCA) and Support vector machine (SVM) model, are combined in a GIS environment for seismic landslide susceptibility assessment. The influencing factors of seismic landslide are selected from Ludian earthquake. The PCA method is applied for dimension-reduced and eliminating physical mining of influence factors. The SVM method is used to establish the seismic landslide susceptibility model. Then the SVM model is applied to assess the landslide susceptibility along Dayong Expressway in Chenghai earthquake-prone area. The flow chart is shown in Figure. 2. 


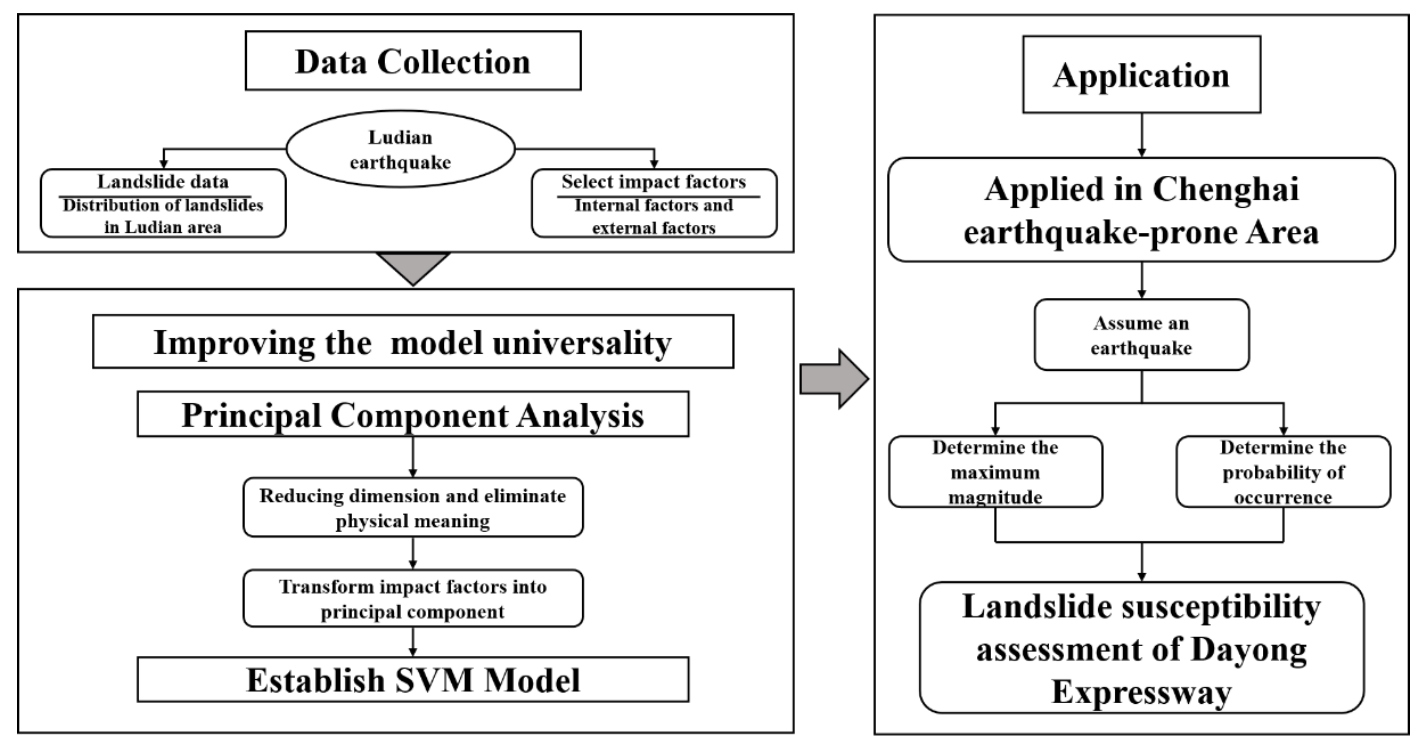

Figure. 2 Flow chart of landslide susceptibility assessment

\subsection{PCA-Based Method}

PCA is a well-known multivariate analysis technique for reducing data dimensions (Lei et al. 2011).

It helps in reducing the data dimensionality by rotating coordinate axes. (Lin et al. 2018). The PCA involves an eigenvalue decomposition to produce eigenvalues and eigenvectors for detecting the change range of data, and transforming high dimensional data into low dimensional data. With the help of principal component analysis, a large number of sample data are replaced by a small number of principal components, which can not only maintain the classification of the original data, but also reduce the dimension of features and eliminate the physical meaning of parameters, so as to facilitate more intuitive and effective classification. The variables obtained after dimensionality reduction contain most of the required information and avoid the interaction between variables. Mathematically, the reduction process is achieved by taking $p$ variables $X_{1}, X_{2}, \ldots, X_{p}$ which are then combined to produce principal components (PCs) $P C_{1}, P C_{2}, \ldots, P C_{p}$, that are uncorrelated. These PCs are also termed eigenvectors (Lei et al 2011). The model between the principal components and the dependent variables is established after the extraction of the principal components. 


\subsection{Support Vector Machine}

The SVM is a commonly used machine learning algorithm that combines the Vapnik-Chervonenkis Dimension from statistics with Structure Risk Minimization Theory. It is widely used in decision-making and prediction in various fields, and can also classify and regress the data. The two main principles of SVM are: the optimal classification hyperplane and the use of a kernel Function (Yao et al. 2008). SVM can also manage linearly inseparable problems by utilizing current data for training and selecting several support vectors from training data to represent all data. Compared to both the logistic regression and neural networks, the support vector machine or the SVM sometimes gives a cleaner and sometimes more powerful way of learning complex nonlinear functions. Illustrations of the basic principles of SVM is shown in Figure. 3. By leading to a mapping function, kernel function maps the sample feature attributes from low dimensional space to high dimensional space, and then transforms the nonlinear classification problem into linear classification problem in high dimensional space. The commonly used kernel functions include: linear kernel function, polynomial kernel function, radial basis function kernel and sigmoid kernel function. According to the experience of some scholars in the application of landslide susceptibility classification, the Gaussian kernel function is selected for training which has the advantages of less training parameters and low complexity of the model. The calculation process is as follows Eq. (1)

$$
K\left(x_{1}, y_{1}\right)=e^{-y\left(x_{1}-x_{2}\right)^{2}}
$$




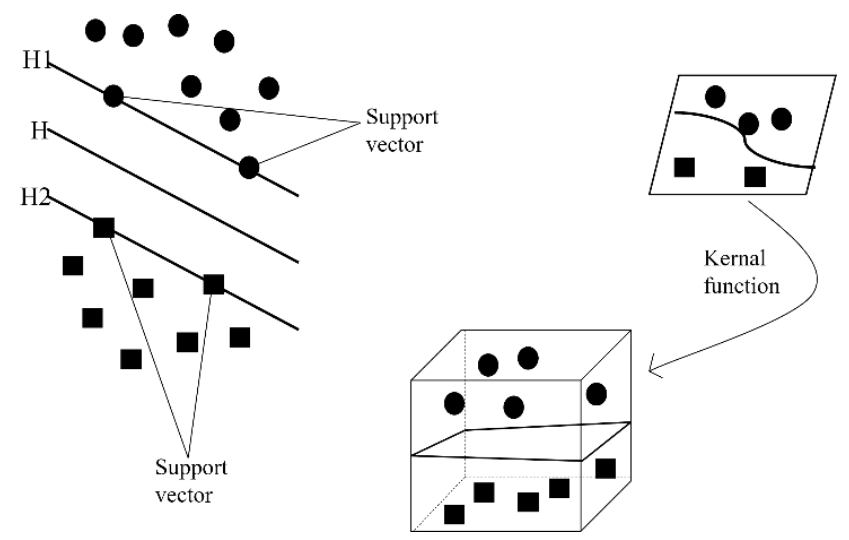

Figure. 3 Illustrations of the basic principles of SVM

\section{Susceptibility assessment model of seismic landslides based on historical earthquake}

\subsection{Ludian earthquake disaster}

On August 3, 2014 (at 4:30 pm), the Ms6.5 earthquake occurred in Ludian County, Zhaotong City, Yunnan Province. The epicenter of the earthquake located at $27.1^{\circ} \mathrm{N}, 103.3^{\circ} \mathrm{E}$ and the focal depth was 12km (Tang et al. 2019). Ludian earthquake was caused by the Baogunao-Xiaohe fault. The BaogunaoXiaohe fault is composed of several discontinuous faults with a total length of about $40 \mathrm{~km}$ (Fu et al. 2020). Field surveys and UAV tilt photography conducted by Earthquake Administrator in Yunnan Province after the earthquake recognized 716 landslides in total (Figure. 4). This damaging earthquake caused approximately 400 deaths, 1800 injuries, and the destruction of at least 12,000 houses (Zhang et al. 2021).

Ludian area is located in the northwest of the Yunnan-Guizhou Plateau, the high terrain west and low in the east in $440-4000 \mathrm{~m}$, most of the slopes are inclined at angles between $15^{\circ}$ and $40^{\circ}$. The strata in this area are mainly Devonian, Permian limestone, marlite and dolomite, with vertical joints developed. In addition, Ludian earthquake area is also affected by the geological fault movement. Therefore, ancient and modern landslides are densely developed (Tang et al. 2019). 

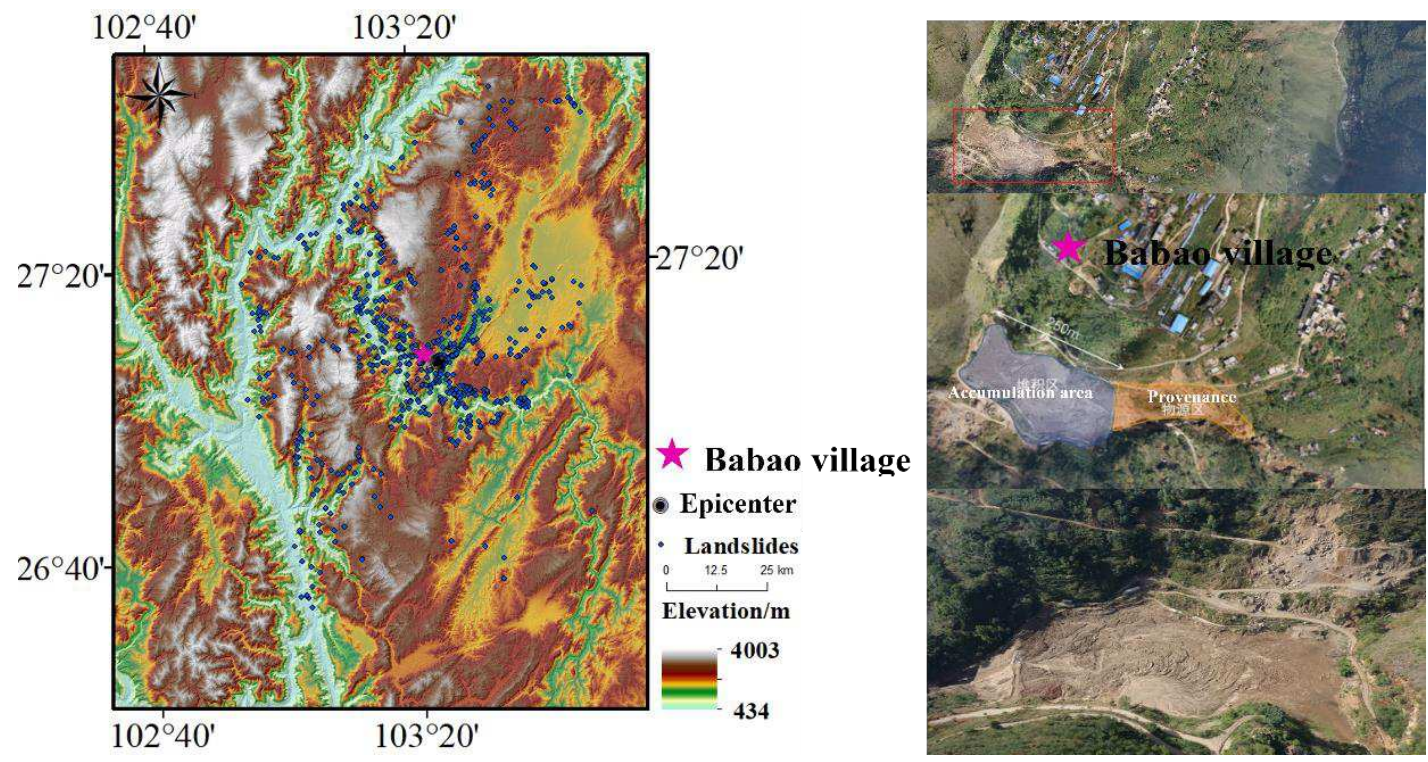

Figure. 4 Landslide distribution of the Ludian area

\subsection{Landslide influence factors}

Based on previous research, Landslides are triggered by various processes including geological, geomorphological, meteorological factors, human engineering activities, groundwater level coefficient and ground motion (Nanda et al. 2020). There is no unified standard for the selection of assessment indexes. The landslides in Ludian area are affected by the earthquake and triggered by both internal and external factors. In this study, the external incentive factors of seismic landslides mainly consider earthquake factors, including epicenter distance and PGA. In addition, eight factors including elevation, slope, slope direction, distance to stream, distance to fault, geology, terrain wetness index (TWI) and normalized difference vegetation index (NDVI) were selected as internal influencing factors. The selection and sources of indicators are shown in Table 1, and the elevation, slope, slope direction and terrain wetness index are calculated by DEM grid map in ArcGIS.

Table 1 Selection of assessment indexes

\begin{tabular}{|c|c|c|c|c|}
\hline First class & Second class & Third class & Data & Type \\
\hline \multirow[t]{2}{*}{ External factors } & Seismic factor & $\begin{array}{l}\text { Horizontal } \\
\text { PGA }\end{array}$ & PGA records of seismic stations & $\begin{array}{l}\text { Data } \\
\text { sheet }\end{array}$ \\
\hline & & $\begin{array}{l}\text { Epicenter } \\
\text { distance }\end{array}$ & DEM & $\begin{array}{l}\text { Raster } \\
\text { map }\end{array}$ \\
\hline
\end{tabular}




\begin{tabular}{lllll} 
Internal factors & $\begin{array}{l}\text { topographic } \\
\text { features }\end{array}$ & $\begin{array}{l}\text { Elevation } \\
\text { Slope } \\
\text { Aspect }\end{array}$ & $\begin{array}{l}\text { DEM } \\
(30 \mathrm{~m} \text { accuracy })\end{array}$ & $\begin{array}{l}\text { Raster } \\
\text { map }\end{array}$ \\
& Hydrogeology & $\begin{array}{l}\text { Distance to } \\
\text { stream }\end{array}$ & & \\
& TWI & & Vector \\
Geology & Geology & geological map & image \\
& & Distance to & $(1: 200000$ scale $)$ & Raster \\
& fault & & map \\
Inventory of & Landslide area distribution & Vector map of original landslide & Vector \\
landslides & NDVI & modis $(16$ day NDVI data, 250m & Raster \\
\hline
\end{tabular}

\subsection{Analysis of spatial distribution characteristics of landslides}

\subsection{Assessment model}

The landslide and non-landslide units in the study area are shown in the Figure. 5. A circular area is set up around the landslide units as a buffer zone, the buffer zone is considered as the scope of landslide, the non-landslide units are randomly generated outside of the buffer area. In this paper, a DEM with a resolution of $30 \times 30 \mathrm{~m}$ is adopted to the grid computing units of the study area. According to the landslide inventory map, there are 716 slope units containing the entire known landslide body. Therefore, the 716 slope units that experienced landslides were used as the modeling data. To meet the modeling requirements and improve the operation accuracy, the 3 times number of non-landslide units (2130) were randomly selected at least $1000 \mathrm{~m}$ away from the landslide units. 


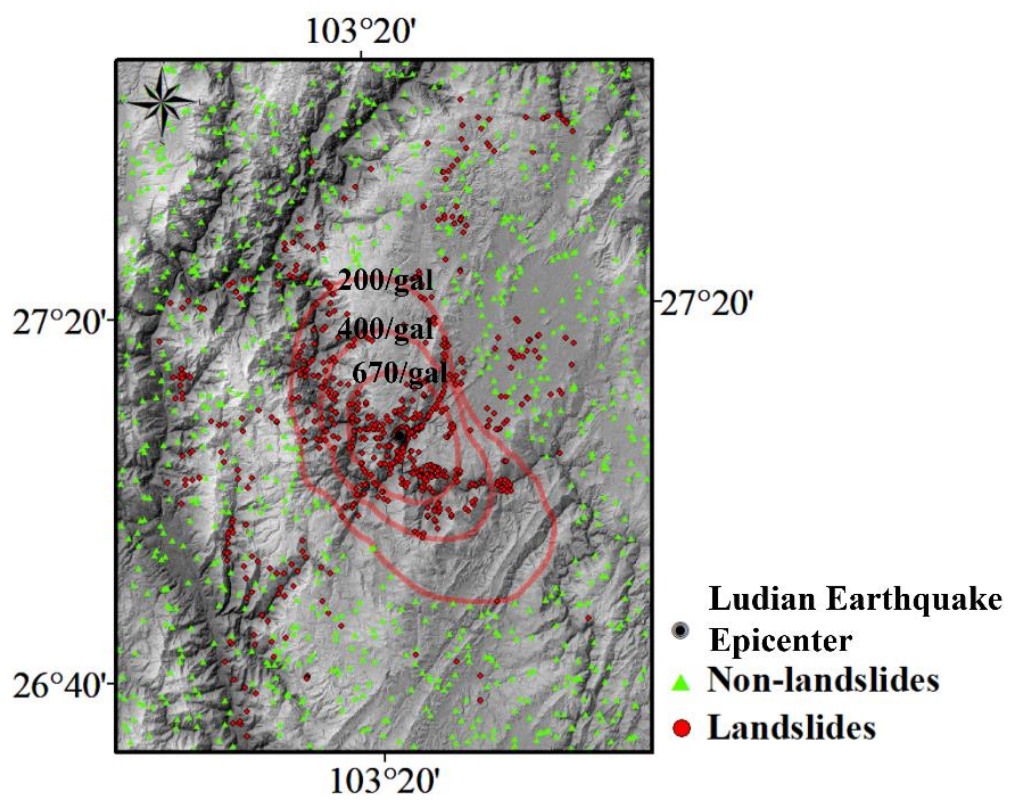

Figure. 5 The landslides units and non-landslides units digital map in Ludian area.

\subsubsection{Analysis results of PCA}

In order to find the correlation between the various factors, numerical standardization is required for the value of influence factors. $\mathrm{Eq}(2)$ is implement to normalize the values of the impact factors of Ludian seismic landslide.

$$
x_{i}^{\prime}=\frac{x_{i}-x_{\min }}{x_{\max }-x_{\min }}
$$

Where $x_{i}^{\prime}$ and $x_{i}$ indicate the normalized and original values of each impact factor, $x_{\max }$ and $\mathrm{x}_{\min }$ indicate the maximum and minimum values of each impact factor.

A large number of input variables could prevent the SVM model find the optimal solution. Furthermore, the SVM model may need many samples for training to avoid over fitting when face to the high dimensional input data. The grid number of Chenghai study area is $656 \times 1140$, and 10 influence factors of seismic landslide susceptibility assessment. The dimensions of eigenvector in Chenghai area are 7478400. However, the landslide sample for training in Ludian area is less. PCA method is used to extracting feature vectors and reducing the number of input variables. Through Spearman's rank 
correlation coefficient, the linear correlation relationships of influence factors are summarized as follows table 2. It proves that there is low linear correlation between the influencing factors. It is reasonable and feasible to extract the susceptibility assessment indexes of Ludian seismic landslide according to PCA method.

Table 2 Component matrix in Ludian area

\begin{tabular}{|c|c|c|c|c|c|c|c|c|c|c|}
\hline $\begin{array}{l}\text { Component } \\
\text { matrix }\end{array}$ & Elevation & Slope & $\begin{array}{l}\text { Slope } \\
\text { direction }\end{array}$ & Geology & $\begin{array}{l}\text { Distance } \\
\text { to } \\
\text { stream }\end{array}$ & $\begin{array}{l}\text { Distance } \\
\text { to fault }\end{array}$ & NDVI & PGA & TWI & $\begin{array}{l}\text { Epicenter } \\
\text { distance }\end{array}$ \\
\hline Elevation & 1 & & & & & & & & & \\
\hline Slope & 0.141 & 1 & & & & & & & & \\
\hline $\begin{array}{l}\text { Slope } \\
\text { direction }\end{array}$ & 0.023 & 0.023 & 1 & & & & & & & \\
\hline Geology & 0.049 & 0.136 & 0.012 & 1 & & & & & & \\
\hline $\begin{array}{l}\text { Distance to } \\
\text { stream }\end{array}$ & 0.005 & 0.089 & -0.021 & 0.124 & 1 & & & & & \\
\hline $\begin{array}{l}\text { Distance to } \\
\text { fault }\end{array}$ & 0.005 & 0.089 & -0.021 & 0.124 & 0.385 & 1 & & & & \\
\hline NDVI & 0.42 & 0.18 & -0.014 & -0.005 & 0.103 & 0.103 & 1 & & & \\
\hline PGA & -0.073 & 0.123 & 0.041 & 0.094 & -0.352 & -0.352 & 0.058 & 1 & & \\
\hline TWI & 0.165 & 0.894 & -0.005 & 0.086 & 0.078 & 0.078 & 0.187 & 0.111 & 1 & \\
\hline $\begin{array}{l}\text { Epicenter } \\
\text { distance }\end{array}$ & 0.149 & 0.126 & -0.03 & -0.121 & 0.127 & 0.127 & 0.1 & 0.689 & 0.113 & 1 \\
\hline
\end{tabular}

Table 3 Results of PCA method in Ludian area

\begin{tabular}{llllllll}
\hline Principal components & & $\mathrm{P}_{1}$ & $\mathrm{P}_{2}$ & $\mathrm{P}_{3}$ & $\mathrm{P}_{4}$ & $\mathrm{P}_{5}$ & $\mathrm{P}_{6}$ \\
\hline & Elevation & 0.561 & -0.210 & 0.243 & -0.033 & 0.205 & -0.076 \\
& Slope & -0.228 & $\mathbf{0 . 6 8 4}$ & 0.003 & -0.018 & -0.137 & -0.015 \\
& Slope direction & 0.000 & -0.014 & 0.557 & 0.453 & $\mathbf{- 0 . 6 4 9}$ & 0.169 \\
& Geology & 0.304 & -0.442 & -0.338 & -0.071 & -0.137 & $\mathbf{0 . 6 3 2}$ \\
Eigenvalues & $\begin{array}{l}\text { Distance to } \\
\text { stream }\end{array}$ & 0.423 & -0.347 & 0.148 & -0.112 & -0.114 & -0.576 \\
& $\begin{array}{l}\text { Distance to } \\
\text { fault }\end{array}$ & 0.195 & 0.210 & $\mathbf{0 . 6 5 5}$ & -0.254 & 0.464 & 0.336 \\
& NDVI & 0.397 & 0.480 & -0.335 & 0.018 & -0.025 & -0.004 \\
& PGA & $\mathbf{- 0 . 8 3 6}$ & -0.189 & -0.011 & -0.058 & 0.078 & -0.031 \\
\hline
\end{tabular}




\begin{tabular}{rcccccc}
\hline TWI & 0.028 & -0.045 & -0.085 & $\mathbf{0 . 8 4 9}$ & 0.477 & -0.019 \\
$\begin{array}{l}\text { Epicenter } \\
\text { distance }\end{array}$ & 0.823 & 0.203 & -0.116 & 0.064 & -0.104 & 0.002 \\
$\begin{array}{l}\text { Contribution rates } / \% \\
\text { Accumulative contribution rate/\% }\end{array}$ & 44.106 & 11.822 & 9.677 & 7.753 & 6.812 & 1.011 \\
\hline
\end{tabular}

Table 3 shows, the six principal components represent $81.181 \%$ content of the impact factors. In this table, the most effective factors in seismic landslide distribution are shown by font add thick. Generally, the external factors included PGA and epicenter distance have the most effect on principle components $P_{1}$ that it indicates more than $44 \%$ input variables variance proportions. It is reasonable by taking the impact of the Ludian earthquake on landslides into consideration. Moreover, the slope has the most effect on principle components $P_{2}$, distance to fault have the most effect on principle components $P_{3}, P_{2}$ and $P_{3}$ includes more than $21 \%$ of variables variance proportions.

In order to determine the correlation between the principal component and landslide after PCA dimensionality reduction and prevent the key factors causing landslide from being deleted. The frequency ratio model is used to calculate the relative frequency of landslide in the interval of the influence factors.

$$
F R=\frac{L / L_{1}}{S / S_{1}}
$$

$F R$ is frequency relative of landslide, $L$ is the number of landslide points in the classification, $L_{1}$ is total number of landslide points in research area. $S$ is the acreage of classified area, and $S_{1}$ is the total study area. The line chart of frequency ratio of all influence factors is shown in the Figure. 6, from the frequency ratio results, the landslide frequency under the influence of elevation factor is concentrated in local range, $69.41 \%$ of the landslides are located in $1040-1984 \mathrm{~m}$, but the relative sensitive range of elevation is only between 1427 and $1745 \mathrm{~m}$. In general, the difference is not significant, so it can be considered that elevation is not the main factors of the occurrence of landslides. For the slope and slope direction factors shown in Figure. 6(a), the distribution of landslides in this area is discrete, the highest sensitivity of 
landslide appeared when the slope range is $45.01-52.73^{\circ}$. In addition, it is obvious that the frequency of landslide is decreased when the distance from fault increases. The landslide frequency affected by geology is also concentrated in the local range, $81 \%$ of the landslides occurred in basalt and quaternary system which accounted for $59 \%$ of the study area. According to the statistics of the landslide frequency relative in NDVI, the frequency of landslides is the highest in the range of NDVI index 0.36-0.46, and then the frequency of landslides decreases gradually. The internal factors of hydrogeology includes distance to stream and TWI (Topographic Wetness Index), as the distance to stream increases, the frequency of landslide decreases. The TWI is divided into ten intervals, the second interval have the highest landslide frequency and the TWI is 2.04-3.62 at present. In addition, landslide frequency reaches the second-high point when the TWI range is 11.16-12.64. It can be inferred that a large amount of rainfall before the earthquake increased the soil moisture content and decreased the strength. Therefore, the distance to stream and TWI are suitable as assessment index for the susceptibility of seismic landslides. The relationship between landslide distribution and the external trigger factor of PGA and epicenter distance are show in Figure. 6(b), the curve indicates the frequency of landslides rising with the increase of PGA and epicenter distance. There is no doubt that PGA and epicenter distance are main factors affecting seismic landslide.

In summary, it is observed that the elevation, slope direction, geology, belongs to redundancy factor, the distance to stream, the distance to fault, PGA, NDVI, TWI, epicenter distance belongs to effective factor. There by indicating that the development of landslides is least sensitive to the redundancy factor, and it is the most sensitive to the effective factor. After verification, the result of $F R$ is consistent with that of PCA. Then, input the principal components $P_{1}, P_{2}, P_{3}, P_{4}, P_{5}$, and $P_{6}$ into the seismic landslide susceptibility model established by the SVM. 


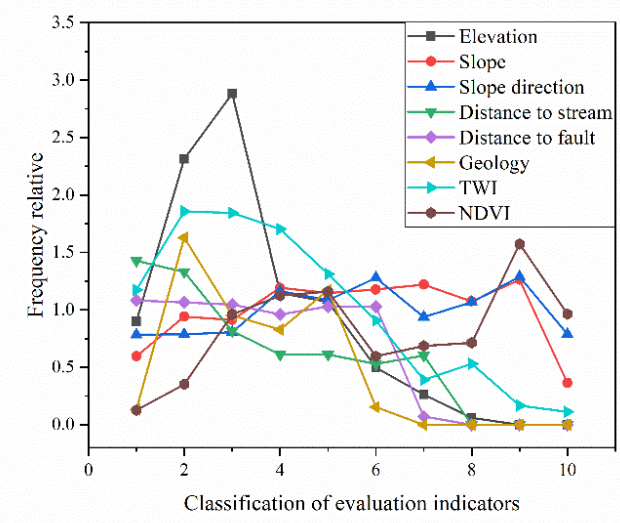

(a)

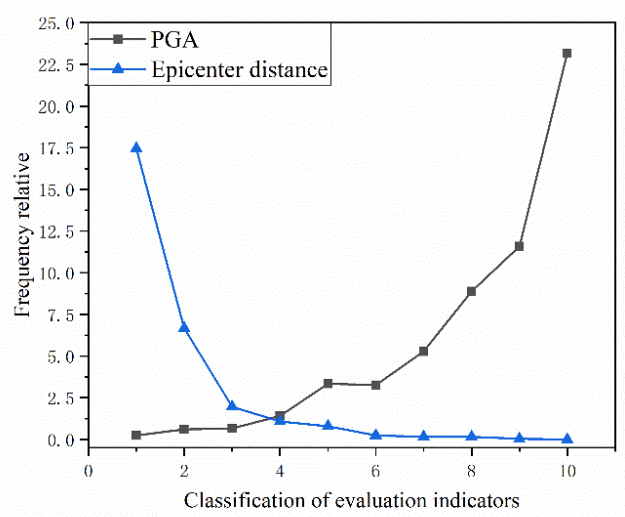

(b)

Figure. 6 Frequency statistics of landslide influence factor. a internal factors. b external factors.

\subsubsection{Model verification}

In the training process of SVM model, the main purpose is to determine the kernel function parameter $\gamma$ and penalty factor $C$. The five-fold cross-validation method was used to validate the models and to overcome the shortage of landslide data and the problem of model overfitting (Yu et al. 2020). The calculation step is to divide the sample into 5 subsets, use 4 subsets for model training, and the remaining 1 subset for verification. By constantly changing the parameter values, the corresponding classification accuracy can be calculated, and then the classification accuracy can be used to determine the optimal parameter combination. Through the above training, we have obtained the optimal kernel function parameter $\gamma$ and penalty factor $C$.

Receiver operating characteristic curve (ROC) is often used as a quantitative analysis method to assessment the prediction accuracy of landslide sensitivity model. The abscissa of the curve is false positive rate $(F P R), N$ is the number of real negative samples, and $F P$ is the number of positive samples predicted by the classifier. The ordinate is true positive rate $(T P R), P$ is the number of real positive samples, $T P$ is the number of positive samples predicted by the classifier. The formula is as follows Eq. 
(4):

$$
T P R=\frac{T P}{P}
$$

Introduce the calculation formula of accuracy using Eq. (5), where $T N$ is the true negative and $F N$ is the false negative.

$$
\text { Accuracy }=\frac{(T P+T N)}{(T P+T N+F P+F N)}
$$

The area under the curve is called AUC (area under ROC curve), AUC is generally between 0.5 and 1 , the larger AUC value indicates that the performance of the model is better. when $\gamma=0.08, C=0.08$, the model accuracy is the highest, $\mathrm{AUC}=94.9 \%$. In order to verify the effect of parameter optimization, the ROC curve of the same SVM model under the original index system is calculated. The ROC curve is as shown in the Figure. 7. The accuracy of the assessment results was improved from $84.3 \%$ to $94.9 \%$ by the optimization of indicators. The comparison results show that the indexes with negligible influence on landslide distribution or contain wrong data are eliminated through landslide frequency analysis and PCA, which improves the accuracy of susceptibility assessment results. 


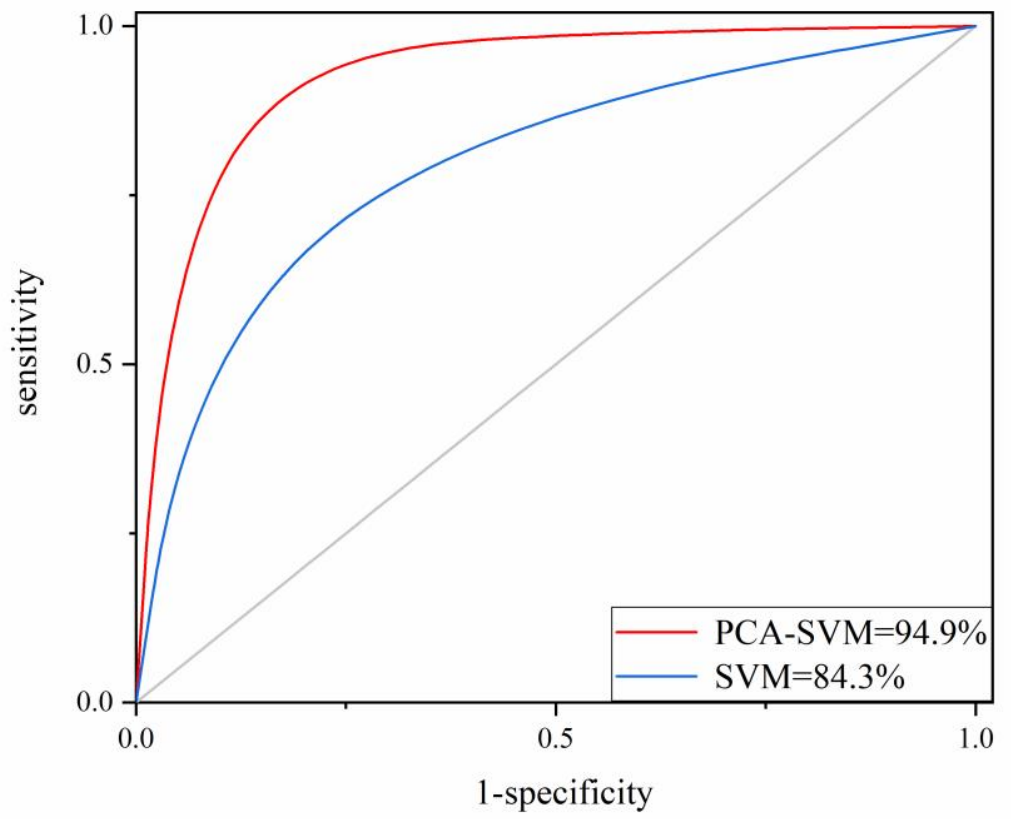

Figure. 7 ROC curve of SVM model

\section{Application in Chenghai earthquake-prone area}

\subsection{Regional seismicity in Chenghai area}

Chenghai fault zone lies to the Midwest of the diamond-shaped Dali fault system and is surround by three regional active faults, including Heqing fault (W), Eryuan-Midu fault (SW), Pingchuan faults (E) and Jianchuan fault (NW). The dense distribution of faults and special geological conditions lead to frequent seismic activities in this area. The strongest earthquake record in history is the Ms7.4 Yongsheng earthquake occurred in 1515. Most of the earthquakes occurred are closely related to these fault structures. From 1970 to 2015, 575 earthquakes with magnitude no less than 3.0 occurred in Chenghai area, including 4 strong earthquakes with magnitude greater than or equal to 6.0. Such as the Yaoan Ms6.5, 2009, Yongsheng Ms4.9, 2019 and Ninglang Ms5.7, 2012. These earthquakes were characterized by frequent occurrences and small magnitudes, they mostly occurred near the fault, thereby indicating that 
the tectonic activity in this area is vigorous (Tang et al. 2020). The fault with the largest effect on the Dayong Expressway is the Chenghai fault. Dayong expressway in the east of Chenghai fault zone. The strike of the line is roughly parallel $60 \mathrm{~km}$ to the Chenghai fault zone, and most of the lines passes through this zone. Once in 1915, the Yongsheng earthquake with Ms7.8 was triggered by the activity of Chenghai fault zone. Figure. 8 describes the historical earthquakes in Chenghai area.

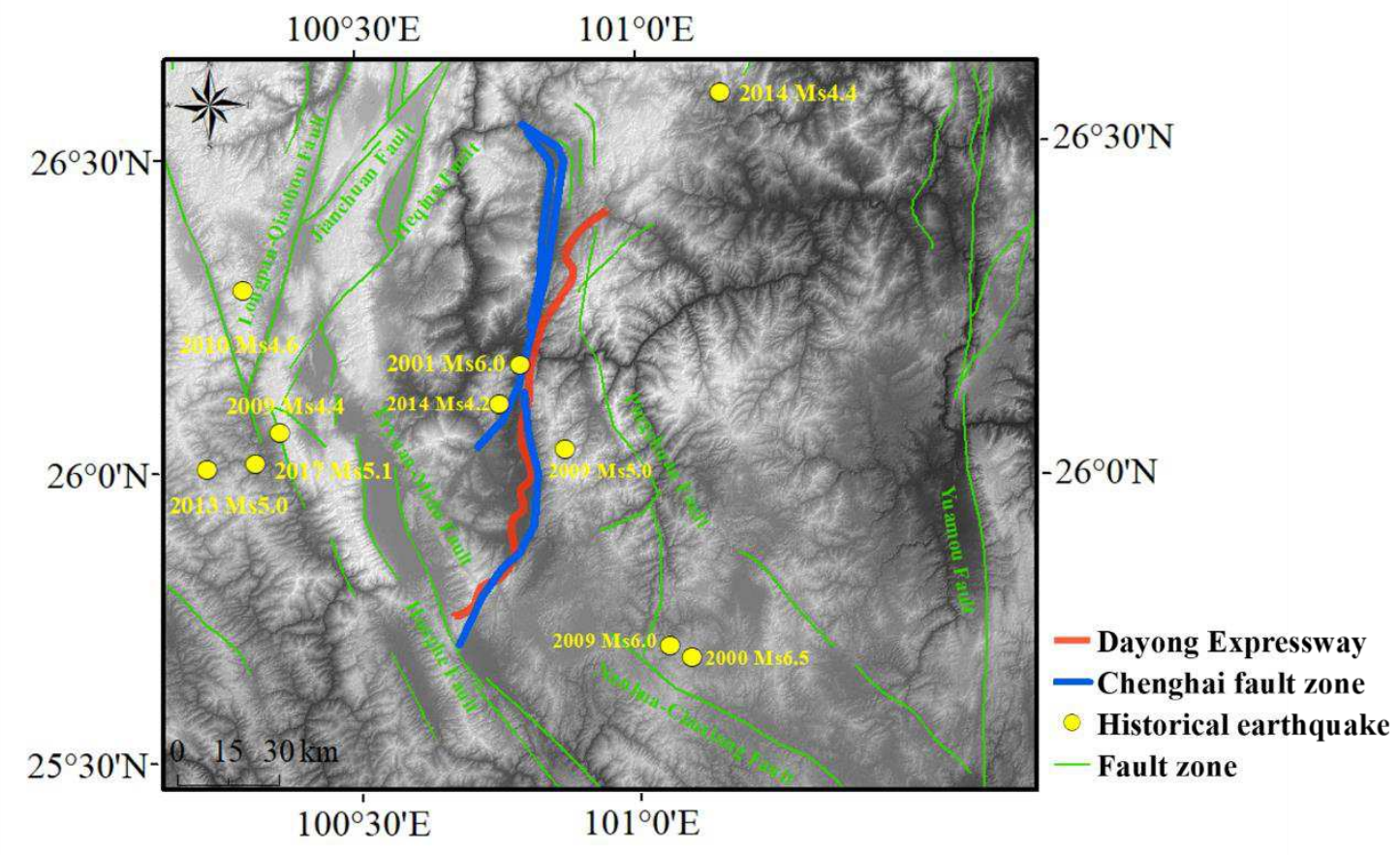

Figure. 8 Regional seismic activity of Chenghai area

Dayong Expressway is a national expressway located in Chenghai area, have twin-four lane, subgrade width of $24.5 \mathrm{~m}$ and the total length is $126 \mathrm{~km}$. In the surrounding area of this expressway, affected by the geological structure and historical earthquakes, many unfavorable slopes are generated, which may cause seismic landslides in the future under external forces (Tang et al. 2020). Based on the analysis of the historical earthquakes in Chenghai area, the surrounding environment of Dayong expressway is affected by Chenghai fault structure, which is most probably to have seismic activity in the future. 


\subsection{Determination of upper bound of regional magnitude based on Gutenberg-Richter (G-R) model}

To apply the SVM model for assessing the seismic landslide susceptibility of Dayong expressway, we assume that an earthquake caused by the Chenghai fault zone in the future. G-R model is used to study the relationship between magnitude and frequency, and then the upper limite of magnitude is determined.

The G-R model is expressed as Eq (6).

$$
\log N(M)=a-b \times M
$$

Where $N(M)$ is the frequency of earthquakes with magnitude greater than or equal to $M, a$ and $b$ are parameters. The G-R model used to fit the regional magnitude-frequency relationship. The seismic statistics are collected in recent ten years (2011-2021) from the Earthquake Administration of Yunnan Province. The magnitude-frequency relation curve shown in the Figure 9. The data is completely and the linear relationship is well when the magnitude is between 2.5 and 6.0, this data is used in G-R model for calculating the maximum magnitude in Chenghai area.

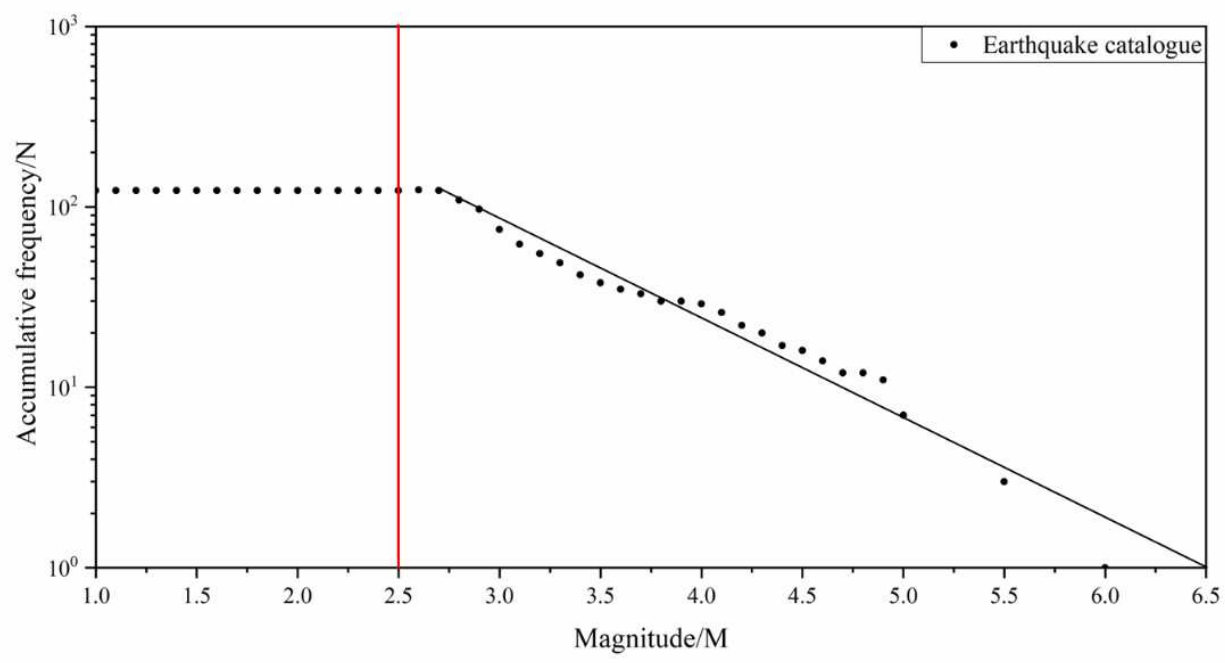

Figure. 9 Magnitude-frequency curves

According to the G-R model and the calculation rules of the least square method, the values of parameters 
$a$ and $b$ can be calculated, $a=4.362, b=0.671$. In general, the upper limite of magnitude is the maximum magnitude that can occur in the region, and the number of occurrences is once. Therefore, through assume the $N\left(M_{\max }\right)=1$, the $M_{\max }$ is calculated. $M_{\max }=6.5$.

Probability of occurrence of maximum magnitude is calculating based to the Dieterich model expressed as $\operatorname{Eq}(7)$.

$$
\begin{array}{r}
R(t)=\frac{r}{\left[e^{\left(-\frac{\Delta C F S}{A \sigma}\right)}-1\right] e^{\left(-\frac{t}{t_{a}}\right)}+1} \\
P=1-e^{(-R)}
\end{array}
$$

where $P$ represents the occurrence probability, $r$ is the frequency of the target seismic magnitude, which is $0.01, \triangle C F S$ is the Coulomb stress, which is $0.024, A \sigma=0.1$, and $t_{a}$ is assumed to be 10 . according to the Dieterich model, the occurrence probability of an Ms6.5 earthquake induced by the Chenghai fault in the next 10 years is $1.1 \%$ (Tang et al. 2020). The epicenter can be located at $26.20^{\circ} \mathrm{N}$ and $100.60^{\circ} \mathrm{E}$. This position is selected as potential epicenter because it is the epicenter of Yongsheng Ms 6.0 earthquake. Yongsheng Ms 6.0 earthquake is induced by the Chenghai fault, and seismicity is vigorous in this area where the latest Ms4.9 earth-quake occurred at $26.16^{\circ} \mathrm{N}$ and $100.62^{\circ} \mathrm{E}$ on July 21 , 2019. We assume that the PGA distribution is the same as that of Ludian earthquake, and obtain the PGA distribution of Chenghai area by Kriging interpolation.

The study area for susceptibility assessment is selected as $100 \mathrm{~km} \times 150 \mathrm{~km}$, which includes the Dayong Expressway and its surrounding environment. The DEM data with the same resolution of $30 * 30 \mathrm{~m}$ was selected in Chenghai study area, selected same factors which affecting landslide as Ludian area.

\subsection{Regional topographic and geological characteristics}


The topographic, geological and groud motion digital map of the study area is obtained by ArcGIS with spatial resolution of $30 \mathrm{~m} \times 30 \mathrm{~m}$ (Fig. 10). The elevation ranges from 1000 to $4000 \mathrm{~m}$, the slope is mostly between 10 and 40 degrees and the terrain is higher in the northeast and northwest. The main strata in the area are Quaternary Holocene, Permian, Carboniferous, and Devonian, which consist of limestone and basalt. Generally, the topographic and geomorphological characteristics in this area are very similar to those in the Ludian area (Tang et al. 2020). Therefore, the landslide susceptibility model based on Ludian earthquake can be applied to landslide susceptibility along the Dayong Expressway in Chenghai earthquake-prone area. The digital map of influence factors in Chenghai area are shown in Fig.

10.
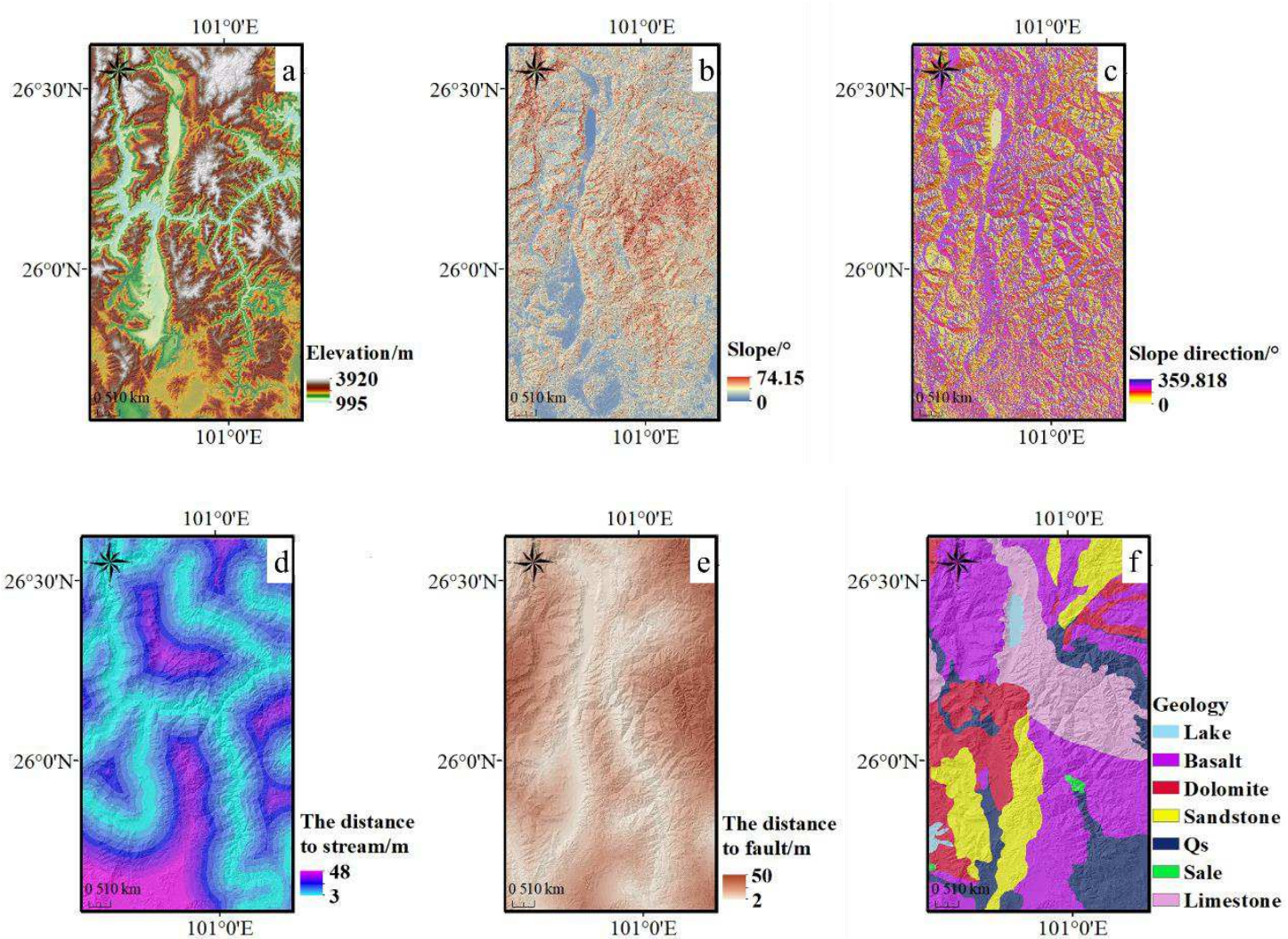

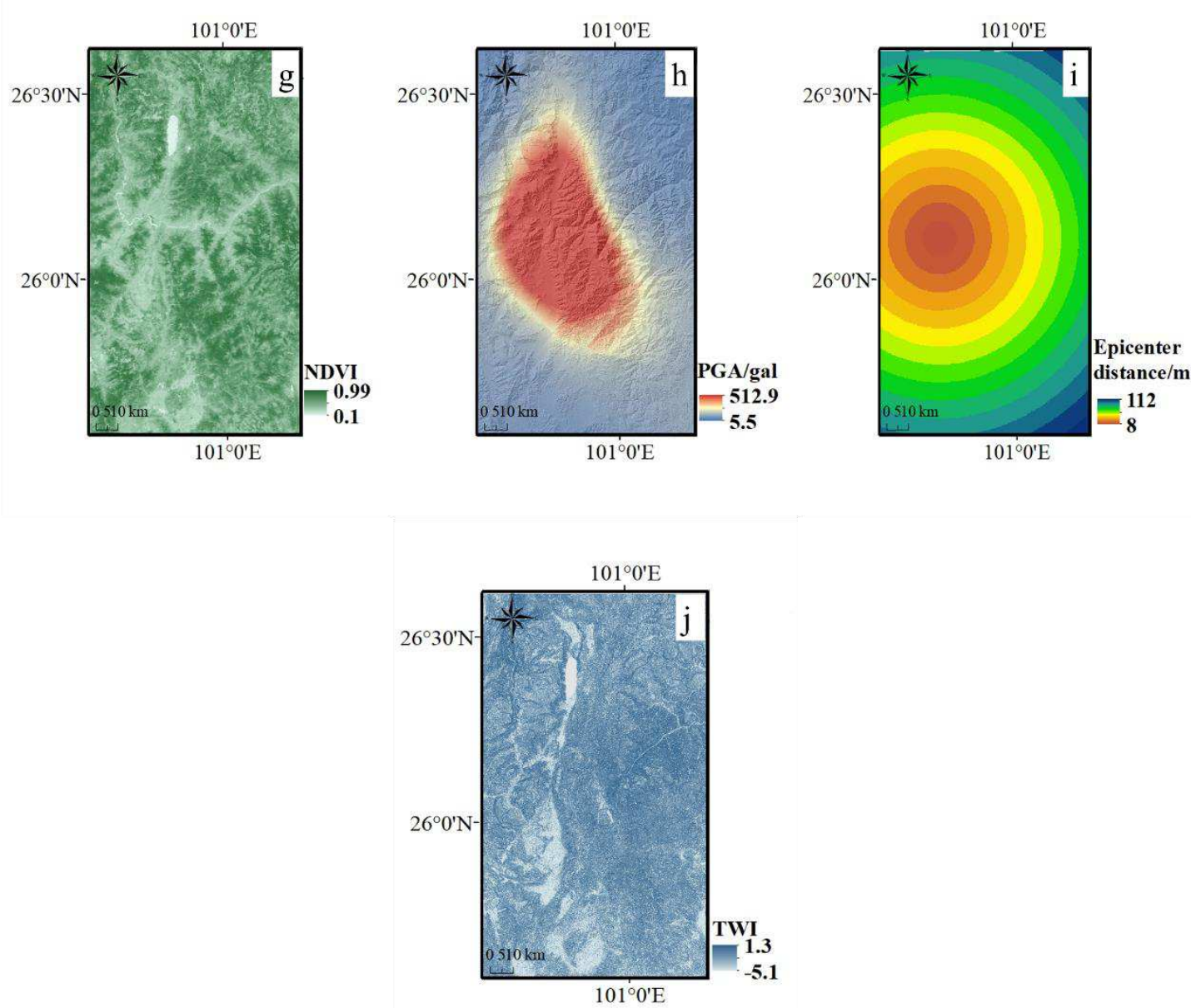

Figure. 10 The influence factors digital map. a Elevation. b Slope. c Slope direction. $\mathrm{d}$ The distance to stream. e The distance to fault. f Geology. g NDVI. h PGA. i Epicenter distance. j TWI.

Through the PCA, six principal components were extracted from ten landslides factors in chenghai area, the six principal components are shown in table 4.

Table 4 Component matrix in Chenghai area

\begin{tabular}{llllllll}
\hline Principle components & $\mathrm{P}_{1}$ & $\mathrm{P}_{2}$ & $\mathrm{P}_{3}$ & $\mathrm{P}_{4}$ & $\mathrm{P}_{5}$ & $\mathrm{P}_{6}$ \\
\hline Eigenvalues & Elevation & 0.232 & 0.269 & 0.544 & 0.471 & -0.05 & 0.023 \\
& Slope & 0.228 & 0.875 & 0.035 & -0.347 & 0.074 & 0.06 \\
& Slope direction & -0.05 & 0.047 & -0.013 & 0.214 & 0.972 & -0.05 \\
& Geology & 0.113 & 0.251 & -0.316 & 0.407 & -0.052 & 0.8 \\
& $\begin{array}{l}\text { Distance to } \\
\text { stream }\end{array}$ & 0.638 & -0.051 & -0.429 & 0.114 & -0.012 & -0.171 \\
& $\begin{array}{l}\text { Distance to } \\
\text { fault }\end{array}$ & 0.638 & -0.051 & -0.429 & 0.114 & -0.012 & -0.171 \\
\hline
\end{tabular}




\begin{tabular}{cccccccc}
\hline NDVI & 0.313 & 0.305 & 0.514 & 0.449 & -0.14 & -0.257 \\
PGA & -0.874 & 0.457 & -0.32 & 0.289 & -0.089 & -0.205 \\
TWI & 0.228 & 0.867 & 0.075 & -0.369 & 0.047 & 0.023 \\
Epicenter & 0.464 & -0.432 & 0.615 & -0.292 & 0.099 & 0.284 \\
distance & 24.228 & 21.488 & 15.161 & 10.867 & 9.955 & 8.949 \\
$\begin{array}{l}\text { Contribution rates/\% } \\
\begin{array}{l}\text { Accumulative contribution } \\
\text { rate/\% }\end{array}\end{array}$ & 24.228 & 45.716 & 60.877 & 71.744 & 81.699 & 90.648 \\
\hline
\end{tabular}

By using PCA method, generous seismic landslide influence factors data is dimension reduction. It is profit to prevent over fitting of SVM model and errors in the assessment results.

\subsection{Landslide susceptibility mapping}

By inputting the dataset from Chenghai area into the SVM model which is trained by using Ludian earthquake data. The landslide susceptibility zoning map of Chenghai area is obtained. According to the classification of the landslide susceptibility by the natural break, the seismic landslide susceptibility values are classified into five classes (Very low, Low, Moderate, High, and Very high). This class is based on natural groupings inherent in the data and boundaries are determined statistically where there are relatively large jumps in the susceptibility data values (Baeza et al. 2016). The seismic landslide susceptibility zoning map is shown in Figure. 11. 


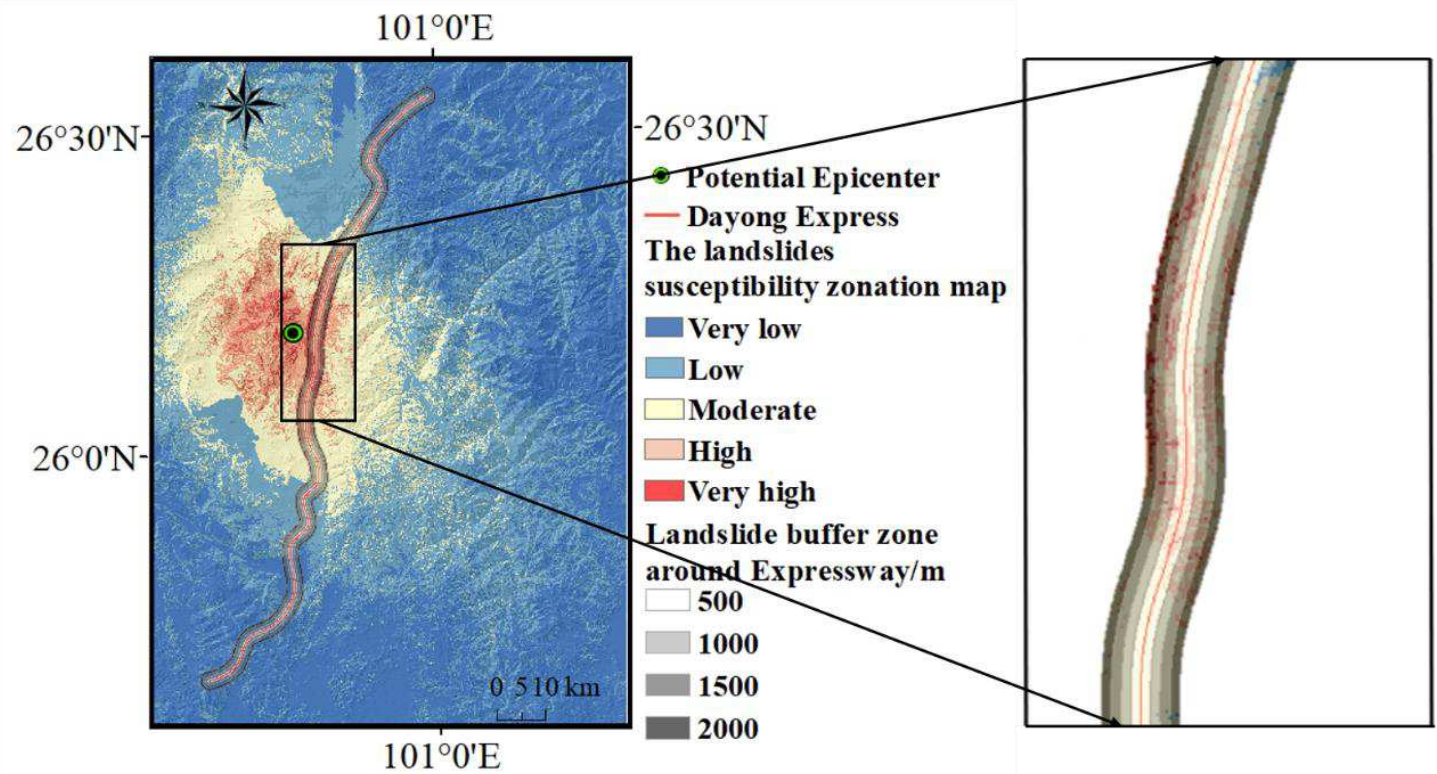

Figure. 11 The seismic landslide susceptibility zoning map

The Figure. 11 shows that the landslide susceptibility class distribution which is similar to the attenuation law of ground motion and decreases gradually from the inside out around the epicenter. The "Very low" class area is represented by dark blue, the colors changing from cold to warm shows that the susceptibility class of landslide increases gradually. The landslide susceptibility mapping show that under the influence of hypothetical ground motions, the "Very high" areas are distributed in the range of $14.5 \mathrm{~km}$ around the earthquake center, accounting for $0.6 \%$ of total area. The spatial distribution is concentrated in the both side and northwest of the epicenter. This area has the highest landslide susceptibility class. As the distance from the epicenter continues to increase, the landslide susceptibility class decline rapidly. It is worth noting that there are still some areas with high landslide susceptibility class in areas over $25 \mathrm{~km}$ from the epicenter, the PGA of these areas is relatively small, this is due to its own internal reasons leading to a higher landslide susceptibility class, such as TWI, slope, etc. The detailed grid data of SVM results are shown in the Figure. 12 (a) and the number of grid cells of susceptibility class is represented by histogram.

\subsection{Assessment results}


According to the results of landslide susceptibility in Chenghai area, the susceptibility degree of landslide in different sections of Dayong expressway is assessed. Based on the assessment principle, the section of expressway is assessed as high-risk class when it passes through the "Very high" landslide prone area or the highest-grade landslide prone points are distributed on both sides. The section of expressway is assessed as moderate-risk class when it passes through the "High" landslide prone area or the high-grade landslide prone points are distributed on both sides. In addition, the expressway through "Moderate", "Low" and "Very low" landslide susceptibility area, there are no high class and above landslide prone points distribute around, the section is identified as low-risk class. The result shows, approximately $35 \%$ of the expressway passes through the "Very high" and "High" landslide susceptibility class area, mainly concentrated in the middle section of Dayong expressway. The coincidence length between the middle section of Dayong Expressway and Chenghai fault zone is about $13 \mathrm{~km}$. The nearest distance is only approximately $4.5 \mathrm{~km}$ away from the Dayong Expressway to earthquake center, which is greatly affected by ground motion and has highest susceptibility class resulting from landslide. In the south and north of the middle section of Dayong expressway, a total of $34 \mathrm{~km}$ section is parallel to Chenghai fault zone. This section passes through "High" landslide susceptibility class area and with high susceptibility landslide prone points nearby. Approximately $60 \%$ of the expressway sections are in moderate and below moderate susceptibility areas.

To further study the hazards of landslide on Dayong Expressway, collecting 54 seismic landslides travel distance to discuss the risk of landslide distance to expressway. The landslide travel distance is from 347 to $4170 \mathrm{~m}$ which triggered by Wenchuan earthquake in 2008 (Guo et al. 2013). Most of the landslides travel distance between 0 and $2000 \mathrm{~m}$. Therefore, a landslide buffer zone is established around Dayong expressway which is divided into four parts from 0 to $2000 \mathrm{~m}$. Figure.11 shows, under an 
assumed earthquake, the landslides travel distance exceed the buffer distance will poses threaten to the Dayong expressway to a certain extent. "Very high" class landslide prone points are concentrated in the buffer zone of 1500-2000 and more than $2000 \mathrm{~m}$. As the travel distance more than $1500 \mathrm{~m}$, the "Very high" class landslide prone points in the buffer zone of 1500-2000 will cause direct damage to the highway pavement. "High" class landslide prone points are distributed in 500-1500 m buffer zones on both sides of Dayong expressway. Furthermore, these "High" class landslide prone points which are close to the Dayong Expressway may cause damage to it. In the 0-500 $\mathrm{m}$ buffer zone which nearest to Dayong Expressway, most of the landslide prone points are "moderate" class, minute quantity of landslide prone points is "High" landslide susceptibility class, and concentrated in the side near the earthquake center. Because the width of expressway pavement is too small compared with Chenghai study area, the landslide buffer zone is regarded as the principal part in landslide susceptibility assessment of Dayong Expressway. Considering that the influence of landslide on Dayong Expressway decreases with the distance, the Inverse Distance Weight (IDW) can be used for determination of landslide risk class of Expressway. The IDW gridding method can be either an exact or a smoothing interpolator. With IDW, data are weighted during interpolation such that the influence of one point relative to another declines with distance from the grid node (Maleika et al. 2020). The IDW is used to interpolating of landslide prone points in the buffer zone, comprehensive consideration of landslide susceptibility class and the distance to Dayong Expressway (Fig .13). And the landslide risk class is divided by using natural break method. Figure. 12(b) shown proportion of sections in Dayong Expressway with different landslide risk class. High-risk sections account for $8.9 \%$ of the total expressway which are most vulnerable to landslides, moderate-risk sections account for $37.1 \%$, it is 
located on the north and south sides of high-risk sections. The low-risk sections are located on the north and south sides of Dayong Expressway and has the largest proportion 54\%.

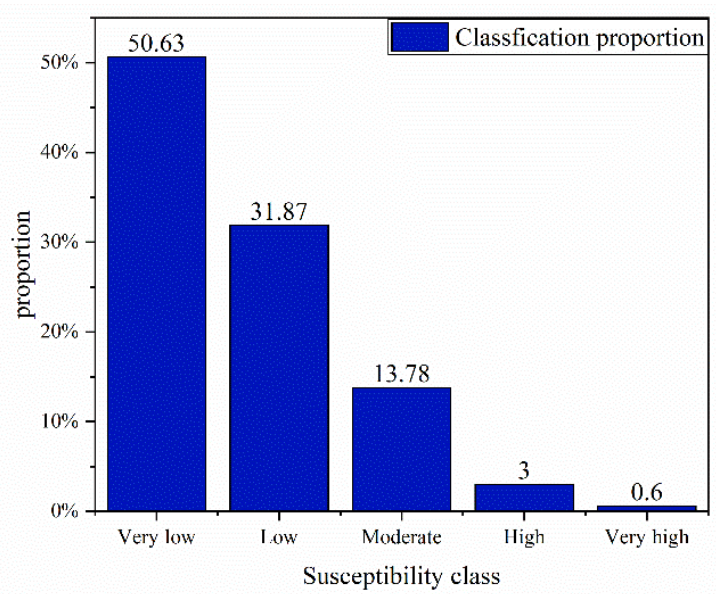

(a)

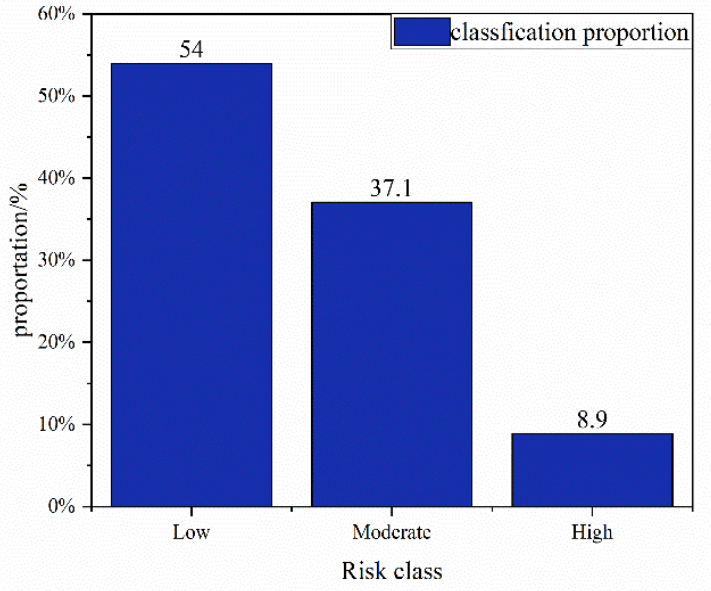

(b)

Figure. 12 (a)Statistics of grid data of landslides susceptibility class of Chenghai area. (b) Statistics of grid data of risk class sections of Dayong Expressway.

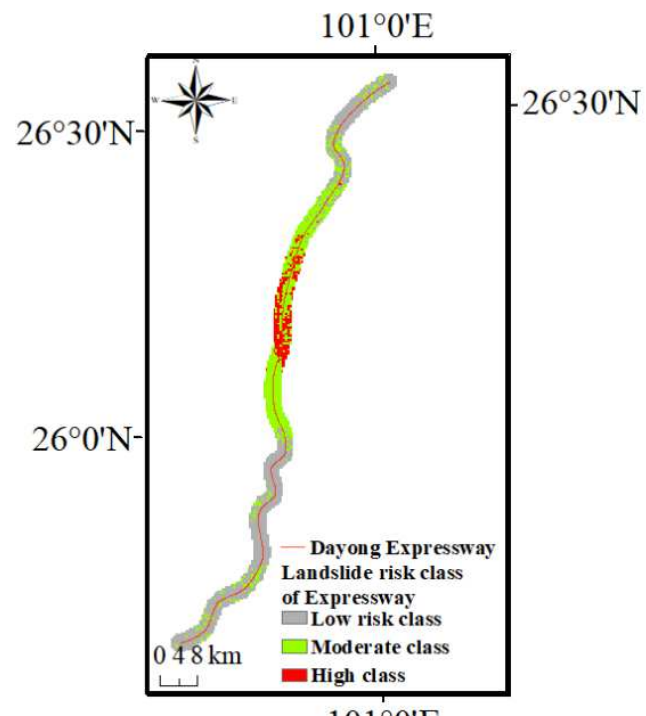

Figure. 13 Landslide risk class of Dayong Expressway

\section{Conclusions}


(1) In this study, 10 influencing factors include internal and external factors are selected as the landslide susceptibility assessment indexes based on the Ludian earthquake. On account of the uniformity of index spatial distribution and the sensitivity of landslide to index interval, the ten seismic landslide influence factors are eliminated the physical meaning and reduced dimension by principal component analysis. The six-principal components represent $81.18 \%$ content of influence factors. The major effective factor that controls the landslide distribution is the peak ground acceleration (PGA), followed by the slope and epicenter distance. Combined with frequent ratio, the redundancy index is analyzed to verify the rationality of reduction. The reduced index system is used as the input of support vector machine to realize the combination of PCA and SVM. Improving the universal of support vector machine. The results show that the accuracy of support vector machine is improved from $84.3 \%$ to $94.9 \%$, and the assessment effect of SVM after parameter optimization is significantly improved.

(2) Analyzed the historical earthquake activities in Chenghai area, the possibility of earthquake in Chenghai area is relatively large in the future. Because the geological conditions in Chenghai area are similar to those in Ludian area, the two areas are close to each other. Applied the SVM model trained in Ludian area to Chenghai area. In the process, the landslide susceptibility assessment in Chenghai area is obtained. According to the model results, the landslide susceptibility assessment is the optimal for dividing into five classes (Very low, Low, Moderate, High, Very high). As the class increases, the degree of susceptibility increases.

(3) The landslide susceptibility assessment results in the Dayong Expressway region indicate that under an assumed earthquake, the area with the "Very high" landslide susceptibility accounts for $0.23 \%$ and seismic landslide has the most obvious impact on the middle section of Dayong expressway. 
The coincidence length between the middle section of Dayong Expressway and Chenghai fault zone is about $13 \mathrm{~km}$. In the south and north of the middle section of Dayong expressway, a total of $34 \mathrm{~km}$ section is parallel to Chenghai fault zone passed through "High" landslide susceptibility class area. Approximately $54 \%$ of the expressway sections are in moderate and the following landslide susceptibility areas.

(4) The landslide buffer zone is established around Dayong expressway and divided into four parts from 0 to $2000 \mathrm{~m}$. "Very high" landslide susceptibility prone points are concentrated in the buffer zone of 1500-2000 and more than 2000 m. "High" landslide susceptibility prone points are distributed in 500-1500 m buffer zones on both sides of Dayong expressway. Most of the landslide prone points are "moderate" and minute quantity are "High" landslide susceptibility class concentrated in 0-500 m buffer zone. Using IDW to interpolating of landslide prone points in the buffer zone, the landslide risk class of Dayong Expressway is obtained. High-risk sections account for $8.9 \%$, moderate-risk sections account for $37.1 \%$, low-risk sections account for $54 \%$. Considering the maximum magnitude and occurrence probability in Chenghai area, the landslide risk of Dayong Expressway can be borne. 


\section{Acknowledgement}

The landslide data in the Ludian earthquake and regional seismic information in the Dayong Expressway area are provided by the Earthquake Administration of Yunnan Province.

\section{Funding}

This work is financially supported by the National Key R\&D Program of China (2018YFC1504504).

\section{References:}

Ayalew L, Yamagishi H. The application of GIS-based logistic regression for landslide susceptibility mapping in the Kakuda-Yahiko Mountains, Central Japan. Geomorphology 2005, 65, 15-31. https://doi.org/10.1016/j.geomorph.2004.06.010.

Baeza C, Lantada N, Amorim S. Statistical and spatial analysis of landslide susceptibility maps with different classification systems. Environ Earth Sci 2016, 75, 1318. https://doi.org/10.1007/s12665016-6124-1.

Bai S, Lu G, Wang J. GIS-based rare events logistic regression for landslide-susceptibility mapping of Lianyungang, China. Environ. Environ. Earth Sci. 2010, 62, 139-149.

Carrara A, Guzzetti F, Cardinali M, et al. Use of GIS Technology in the Prediction and Monitoring of Landslide Hazard. Natural Hazards 1999, 20, 117-135. https://oi.org/10.1023/A:1008097111310

Ge Y, Chen H, Zhao B, et al. A comparison of five methods in landslide susceptibility assessment: a case study from the 330-kV transmission line in Gansu Region, China. Environ Earth Sci 2018,77, 662. https://doi.org/10.1007/s12665-018-7814-7

Eeckhaut M V D, Poesen J, Verstraeten G, et al. The effectiveness of hillshade maps and expert knowledge in mapping old deep-seated landslides. Geomorphology 2005, 67, 351-363. https://doi.org/10.1016/j.geomorph.2004.11.001.

Fu X, Sheng Q, Li G. et al. Analysis of landslide stability under seismic action and subsequent rainfall: a case study on the Ganjiazhai giant landslide along the Zhaotong-Qiaojia road during the 2014 Ludian earthquake, Yunnan, China. Bulletin of Engineering Geology and the Environment 2020, 79, 5229-5248. https://doi.org/10.1007/s10064-020-01890-z.

Guo D, Hamada M, He C. et al. An empirical model for landslide travel distance prediction in Wenchuan earthquake area. Landslides 2014, 11, 281-291. https://doi.org/10.1007/s10346-013-0444-y

He H D, Hu D, Sun Q, et al. A Landslide Susceptibility Assessment Method Based on GIS Technology and an AHP-Weighted Information Content Method: A Case Study of Southern Anhui, China. ISPRS International Journal of Geo-Information 2019, 8.6. doi:10.3390/ijgi8060266.

Hong H Y, Ilia I, Tsangaratoset P, et al. A hybrid fuzzy weight of evidence method in landslide susceptibility analysis on the Wuyuan area, China. Geomorphology 2017, 290, 1-16. https://doi.org/10.1016/j.geomorph.2017.04.002 
Huang Y, Zhao L. Review on landslide susceptibility mapping using support vector machines. Catena 2018, 165:520-529. doi:10.1016/j.catena.2018.03.003.

Huang X L, Wu Z H, et al. The main active faults and tectonic system in Yongsheng area, northwestern Yunnan. Journal of Geomechanics. 2016, 22(3):531-547

Kamila P, Andrzej B. Landslides Identification Using Airborne Laser Scanning Data Derived Topographic Terrain Attributes and Support Vector Machine Classification. ISPRS - International Archives of the Photogrammetry, Remote Sensing and Spatial Information Sciences XLI-B8 2016, :145-149. https://doi.org/10.5194/isprs-archives-XLI-B8-145-2016

Kayastha P, Dhital M R, Smedt F D. Application of the analytical hierarchy process (AHP) for landslide susceptibility mapping: a case study from the Tinau watershed, west Nepal. Computers \& geosciences 2013,52(5):398-408. https://doi.org/10.1016/j.cageo.2012.11.003

Lai J S, Tsai F. Improving GIS-Based Landslide Susceptibility Assessments with Multi-temporal Remote Sensing and Machine Learning. Sensors (Basel, Switzerland), 2019, 19.17. https://doi.org/10.3390/s19173717

Lei T C, Wan S, Chou T Y. et al. The knowledge expression on debris flow potential analysis through PCA + LDA and rough sets theory: a case study of Chen-Yu-Lan watershed, Nantou, Taiwan. Environ Earth Sci 2011, 63, 981-997. https://doi.org/10.1007/s12665-010-0775-0

Maleika W. Inverse distance weighting method optimization in the process of digital terrain model creation based on data collected from a multibeam echosounder. Applied Geomatics 2020, 12(6).

Moragues S, Lenzano M G, Lanfri M, et al. Analytic hierarchy process applied to landslide susceptibility mapping of the North Branch of Argentino Lake, Argentina. Nattural Hazards 2021, 105, 915-941. https://doi.org/10.1007/s11069-020-04343-8

Miloš M, Miloš K, Branislav B, et al. Landslide susceptibility assessment using svm machine learning algorithm. Engineering Geology, 2011, 123(3), 225-234.

Nanda A M, Hassan Z U, Ahmed P, et al. Landslide susceptibility assessment of national highway 1D from Sonamarg to Kargil, Jammu and Kashmir, India using frequency ratio method. GeoJournal 2020, 85.3:01-14. https://doi.org/10.1007/s10708-020-10235-y.

Qin Y Q, Tang H, Deng Q Y et al. Regional seismic slope assessment improvements considering slope aspect and vertical ground motion. Engineering Geology, 2019, 259, 105148-105148.

Sarychikhina O, Palacios D G, Argoteet L A D, et al. Application of satellite SAR interferometry for the detection and monitoring of landslides along the Tijuana - Ensenada Scenic Highway, Baja California, Mexico. Journal of South American Earth Sciences. 2020, 2 doi:10.1016/J.JSAMES.2020.103030.

Tang Y, Che A, Cao Y, et al. Risk assessment of seismic landslides based on analysis of historical earthquake disaster characteristics. Bulletin of Engineering Geology and the Environment 2020, 79, 2271-2284. https://doi.org/10.1007/s10064-019-01716-7.

Vkpa B, Kksa B, Hrp C, et al. Sedimentological characteristics and application of machine learning techniques for landslide susceptibility modelling along the highway corridor nahan to rajgarh (himachal pradesh), india. CATENA, 2019, 182, 104150-104150. doi:10.1016/j.catena.2019.104150

Wang E, Burchfiel B C, Royden L H, et al. Late Cenozoic Xianshuihe /Xiaojiang and Red River fault systems of southwestern Sichuan and central Yunnan, China. Special Paper of the Geological Society of America, 1998, 327: 1-108. 
Wang Y M, Zhang X L, Chen J, et al. Optimizing the predictive ability of machine learning methods for landslide susceptibility mapping using smote for lishui city in zhejiang province, china. International journal of environmental research and public health. 2019, 16.3. https://doi.org/10.3390/ijerph16030368.

Wang Y, Fang Z C, Wang M, et al. Comparative study of landslide susceptibility mapping with different recurrent neural networks. Computers \& Geosciences 2020, 138:104445. https://doi.org/10.1016/j.cageo.2020.104445.

Wei X, Zhang L L, Yang H Q, et al. Machine learning for pore-water pressure time-series prediction: Application of recurrent neural networks. Geoscience Frontiers. 2021, 12(1):453-467. DOI:10.1016/j.gsf.2020.04.011.

Wu R, Zhang Y, Guo C. et al. Landslide susceptibility assessment in mountainous area: a case study of Sichuan-Tibet railway, China. Environ Earth Sci 2020, 79, 157. https://doi.org/10.1007/s12665020-8878-8

Xu C, Shen L, Wang G. Soft computing in assessment of earthquake-triggered landslide susceptibility. Environ Earth Sci 2016, 75, 767. https://doi.org/10.1007/s12665-016-5576-7

Yao X, Tham L G, Dai F C. Landslide susceptibility mapping based on support vector machine: a case study on natural slopes of Hong Kong, China. Geomorphology, 2008, 101 (4), 572-582.

Yu C, Chen J. Landslide Susceptibility Mapping Using the Slope Unit for Southeastern Helong City, Jilin Province, China: A Comparison of ANN and SVM. Symmetry. 2020, 12(6):1047. https://doi.org/10.3390/sym12061047.

Yin C, Li H, Che F, et al. Susceptibility mapping and zoning of highway landslide disasters in China. PloS one 2020, 15.9. doi:10.1371/journal.pone.0235780.

Yusof N M, Pradhan B, Shafri H Z M, et al. Spatial landslide hazard assessment along the Jelapang Corridor of the North-South Expressway in Malaysia using high resolution airborne LiDAR data. Arabian Journal of Geosciences 2015, 8.11:1-12. https://doi.org/10.1007/s12517-015-1937-x.

Yusof N M, Pradhan B. Landslide susceptibility mapping along PLUS expressways in Malaysia using probabilistic based model in GIS. Iop Conference 2014, 20:012031. https://doi.org/10.1088/1755$1315 / 20 / 1 / 012031$

Zhao B, Ge Y, and Chen H. Landslide susceptibility assessment for a transmission line in Gansu Province, China by using a hybrid approach of fractal theory, information value, and random forest models. Environ Earth Sci 2021,80, 441. https://doi.org/10.1007/s12665-021-09737-w

Zhang J, Cui P, Ge Y. et al. Susceptibility and risk assessment of earthquake-induced landslides based on Landslide Response Units in the Subao River basin, China. Environ Earth Sci. 2012, 65, 1037-1047. https://doi.org/10.1007/s12665-011-1002-3.

Zhang J, Lu M, Zhang L, et al. Assessing indirect economic losses of landslides along highways. Natural Hazards. 2021, 106, 2775-2796. https://doi.org/10.1007/s11069-021-04566-3

Zhang Y, Meng Q, Wang Z, et al. Temperature variations in multiple air layers before the mw 6.22014 ludian earthquake, yunnan, china. Remote Sensing, 2021, 13(5), 884. DOI:10.3390/rs13050884.

Zhou C, Yin K L, et al. Landslide susceptibility modeling applying machine learning methods: A case study from Longju in the Three Gorges Reservoir area, China. Computers \& Geosciences 2018, 112:23-37 